\title{
Contraria contrariis curantur: el arte del canon y las habilidades mentales
}

\author{
Fabrizio Ammetto
}

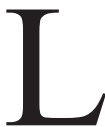

a frase en latín del título de este artículo Contraria contrariis curantur ("los contrarios se curan con los contrarios") no hace referencia a la doctrina de "lo similar cura lo similar" del sistema de la homeopatía (medicina alternativa) creado por Samuel Hahnemann en 1796, sino que es el título de la décima composición musical incluida en la colección impresa Artificii musicali ne quali si contengono canoni in diverse maniere, contrapunti dopii, inventioni curiose, capritii e sonate, ${ }^{1}$ opus XIII (Modena, 1689) del violinista y compositor italiano Giovanni Battista Vitali (1632-1692).

Como afirma el mismo autor en la carta al "amigo lector" al principio de esta impresión musical, "no merece el nombre de Músico quien no sabe utilizar de cualquier forma los secretos más profundos del Arte [...] por ser los Cánones en realidad el verdadero examen del Contrapunto" (Vitali, 1689: 5).

En la composición musical, el canon es una pieza de carácter contrapuntístico basada en la imitación entre dos o más voces, separadas por un intervalo temporal. Una parte vocal o instrumental interpreta una melodía y después una segunda voz repite esa misma melodía de manera exacta o bien modificando algunos de sus aspectos. A la primera voz se le llama $d u x$ (propuesta o antecedente), y a cada una de las voces que le siguen comes (respuesta o consecuente). Un tipo particular de canon es el canon enigmático, en el que el autor no ha dejado expresamente escrito el tema canónico y/o sus consecuentes, sino solamente la primera voz $(d u x)$, y ha de ser el intérprete el que previamente debe buscar dónde empieza/n la/s respuesta/s, decidiendo el desfase temporal entre las partes, el intervalo y, eventualmente, otras características rítmicas o melódicas.

1 Traducción: "Artificios musicales que contienen cánones de diferentes tipos, contrapuntos dobles, invenciones curiosas, caprichos y sonatas".
En el Renacimiento y en el Barroco, los cánones eran considerados como una de las formas musicales más importantes para el estudio del contrapunto y de la composición musical. ${ }^{2}$ Las habilidades mentales que pueden desarrollarse en un estudiante de música gracias a la correcta resolución de cánones y otros enigmas musicales son verdaderamente notables, aunque -hoy en díasubestimadas; ${ }^{3}$ por esta razón, considero este tipo de entrenamiento como un excelente, estimulante y entretenido material didáctico.

En el opus XIII de Vitali, de acuerdo con sus mismas palabras, algunos de estos cánones "están aclarados, otros son artificiosos y rigurosos con frases enigmáticas, reflexionando sobre ellas encontrarás la solución, y otros con la inteligencia de los reversos y contrarios, y finalmente algunos

2 Ver Alberto Basso. (2004).

3 De hecho, en la actualidad, si por un lado se siguen estudiando en todo mundo obras maestras del contrapunto riguroso de Johann Sebastian Bach (1685-1750) -tales como las Goldberg-Variationen (Bwv 988), la Musikalisches Opfer (Bwv 1079), Die Kunst der Fuge (Bwv 1080), entre otras-, por otro lado las posibles soluciones alternativas de sus Canones über die ersten acht Fundamental-Noten vorheriger Arie (BWv 1087) están todavía en espera de encontrarse. 
necesitan no de la crítica sino del estudio" (Vitali, 1689: 5).

En el canon a tres voces contraria contrariis curantur, Vitali indica con un símbolo $(« \bullet \mathrm{S} \bullet)=$ solución) el punto exacto donde tienen que empezar la segunda y la tercera voz (Imagen 1); sin embargo, es evidente que las primeras tres notas del ca- non (la, sol, fa) no encajan musicalmente junto con las notas 2-3-4 (sol, fa, fa) del compás 3, donde tendría que empezar la segunda voz. La solución de este canon está escondida en su título en latín: si la segunda voz se mueve por movimiento "contrario" todo funcionará (Imagen 2).

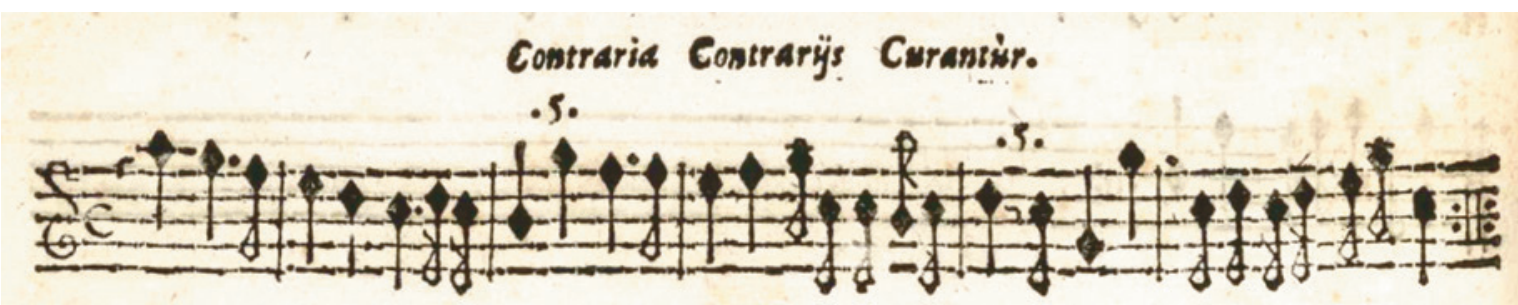

Imagen 1. Giovanni Battista Vitali, Canon "Contraria contrariis curantur” (impresión original de 1689).
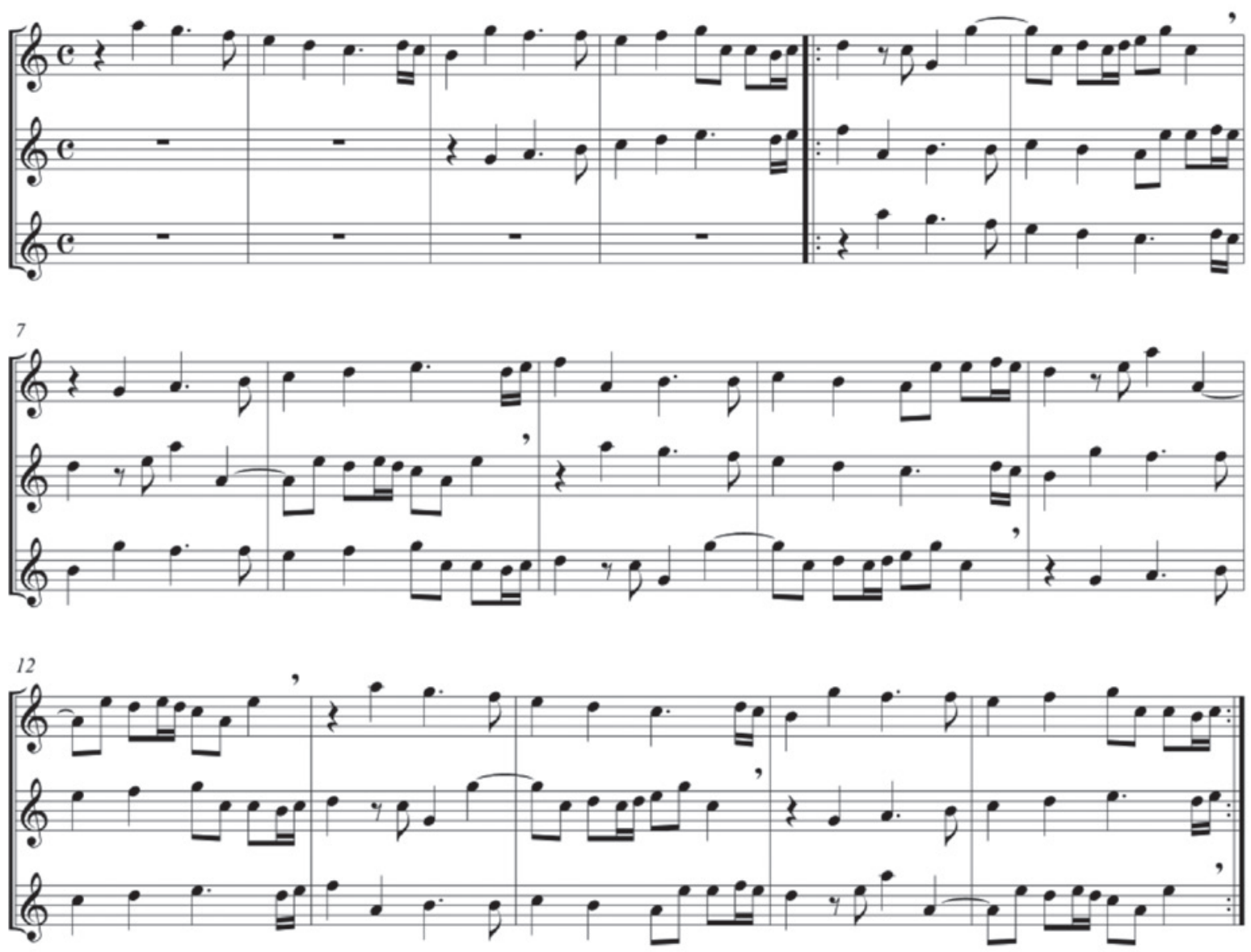

Imagen 2. Giovanni Battista Vitali, Canon "Contraria contrariis curantur" (solución). 
El título en latín del canon no. 11 del opus XIII de Vitali es "De minimis non curat prcetor" (Imagen 3), cuyo significado es "el pretor no se ocupa de cosas mínimas". Esta frase no parece tener mucho sentido en un contexto musical; sin embargo, la solución está en el juego del doble significado de la palabra minimis, "cosas mínimas", pero también "blancas", en el sentido de figuras musicales. Así que, si en la transcripción del canon se omiten todas las figuras musicales correspondientes a las blancas, el canon a tres voces al unísono estará perfectamente resuelto (Imagen 4).
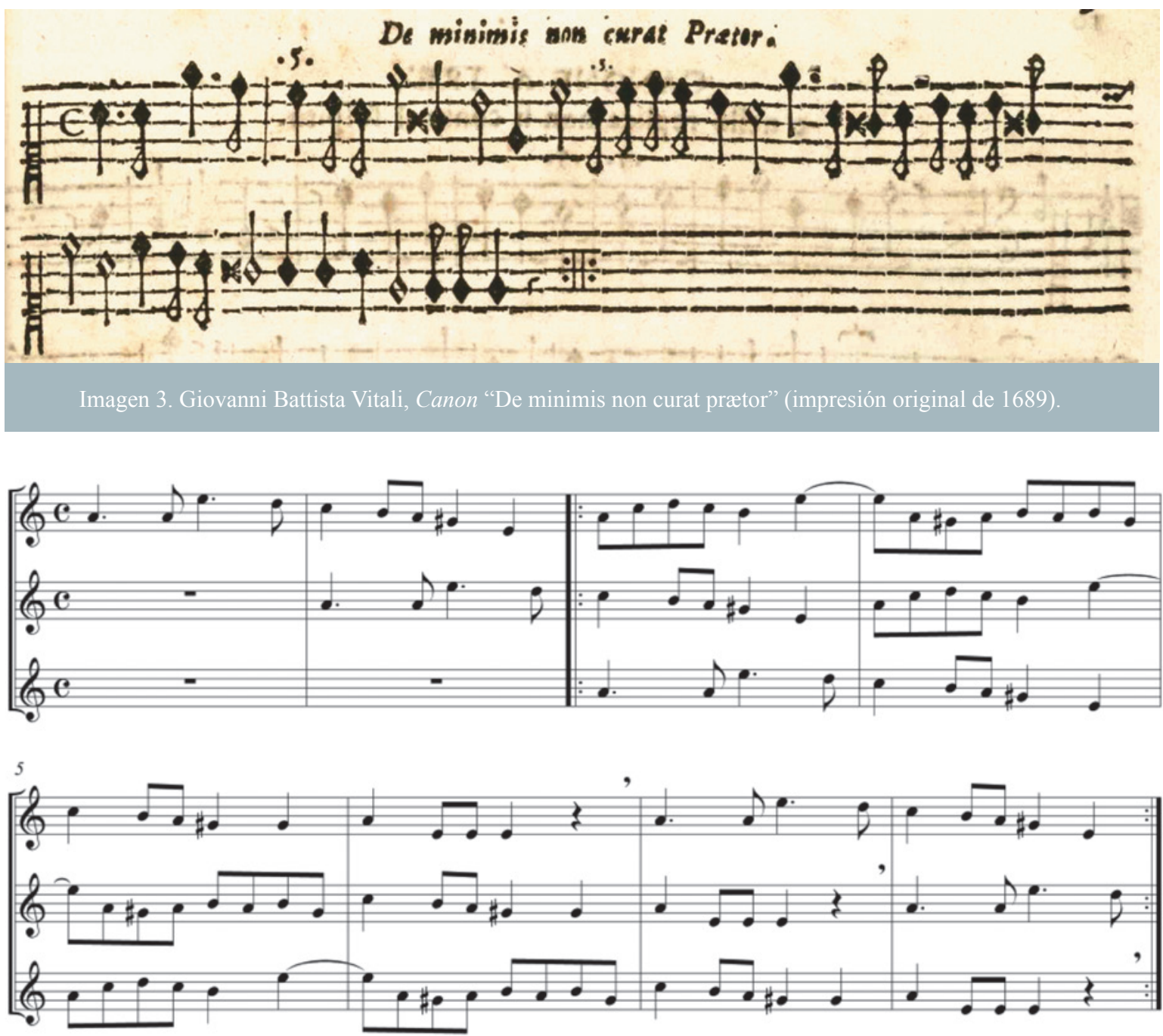

Imagen 4. Giovanni Battista Vitali, Canon "De minimis non curat prætor" (solución).

La composición no. 2 del opus XIII de Vitali es muy interesante, también a nivel visual (Imagen 5). El título es "Cantilena à quattro" ("Cantilena a cuatro"), y en el índice del contenido de la colección se especifica que es una "Cantilena à quattro in ruota" ("en rueda", o sea en círculo). Hay un círculo en donde están ubicadas 28 notas, debajo de las cuales aparece un verso en latín Fortunce solum virtus fuit semper verax dux: variat illa vices, manet illa fixa lux, cuyo significado es "solamente la virtud ha sido siempre la verdadera guía del destino: cambia el destino, permanece aquella luz fija". Dentro del círculo aparecen también cuatro claves musicales: de soprano, contralto, tenor y bajo. Evidentemente, se trata de un canon circular a cuatro voces -como nos indican las cuatro claves-, pero 
no está especificado ni el punto en donde las tres respuestas tienen que empezar, ni el intervalo musical de cada una de las voces. ${ }^{4}$

Para encontrar la solución de esta breve composición, dejo reflexionar a los lectores atentos de esta revista -en particular a los estudiantes de música-, recordando que se necesita "no de la crítica sino del estudio" (Vitali, 1689: 5).

Como afirma Alberto Basso, "si [en el Barroco] la música es un enigma, una práctica oculta y secreta, entonces será en el arte del canon que ésta encontrará la manera más apropiada para manifestarse en toda su magnitud" (Basso, 2004: 608).

4 En 1959, Louise Rood y Gertrude P. Smith propusieron una solución de esta "Cantilena" que, según las palabras de ellos mismos, "the editors have failed to discover": ver Rood, L.; Smith, G. P. (1959: 2). Giovanni Battista Vitali, Artificii musicali, Op. 13. Northampton, Mass., Smith College, p. 2.

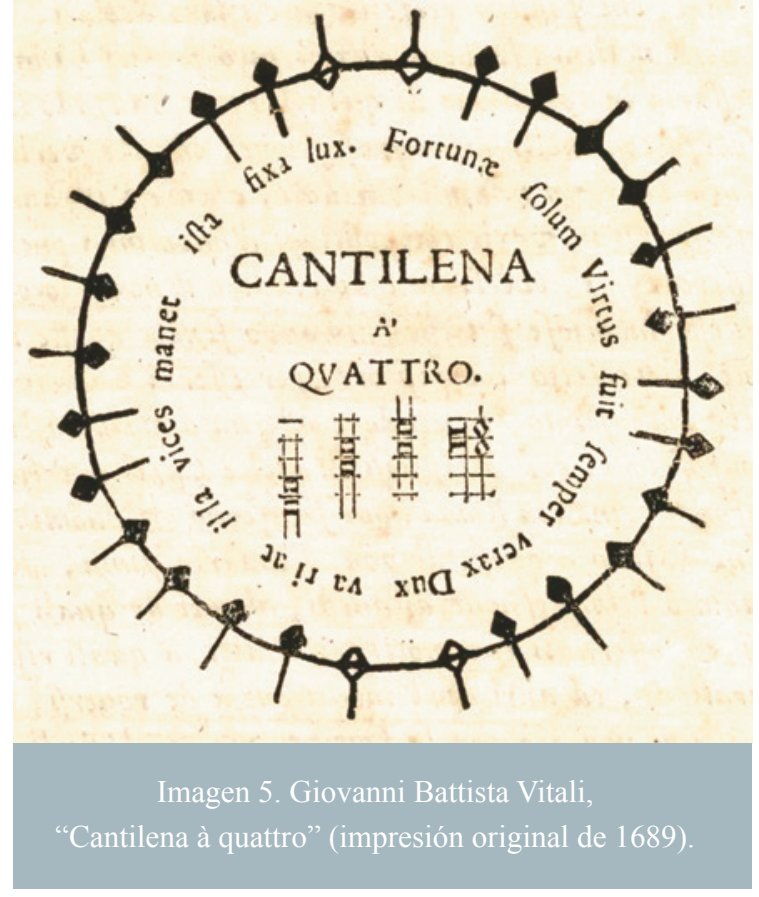

\section{Fuentes de consulta}

Bach, J. S. (1741-1747). Canones über die ersten acht Fundamental-Noten vorheriger Arie. BWV 1087, manuscrito (en Bibliothèque nationale de France).

Bach, J. S. (1745-1749). Die Kunst der Fuge. Bwv 1080, manuscrito (en Staatsbibliothek zu Berlin).

Bach, J. S. (1741). Goldberg-Variationen. BWv 988, Núremberg, Balthasar Schmid.

Bach, J. S. (1747). Musicalisches Opfer. Bwv 1079, manuscrito (en Staatsbibliothek zu Berlin).

Basso, A. (2004). Massoneria, esoterismo e altri luoghi segreti della musica dei secoli XVII-XIX (606-611). En Jean-Jacques Nattiez (Ed.).
Enciclopedia della musica, IV (Storia della musica europea). Giulio Einaudi Editore: Torino.

Jean-Jacques N. (Ed.). (2004). Enciclopedia della musica, IV (Storia della musica europea). Giulio Einaudi Editore: Torino.

Rood, L. - Smith, G. P. (1959). Giovanni Battista Vitali, Artificii musicali, Op. 13. Northampton, Mass., Smith College.

Vitali, G. B. (1689). Artificii musicali ne quali si contengono canoni in diverse maniere, contrapunti dopii, inventioni curiose, capritii e sonate, opus XIII. Modena: Eredi Cassiani. 